\title{
Microhardness and Nano-hardness Measurement of Composite Coatings Applied to Alumi- nium Substrate
}

\author{
Jaroslava Svobodová1, Irena Lysoňková ${ }^{1}$, Miroslav Krejčí ${ }^{2}$ \\ ${ }^{1}$ Faculty of Mechanical Engineering, University of J. E. Purkyně in Ústí nad Labem. Pasteurova 3334/7, 400 96 Ústí nad \\ Labem. Czech Republic.E-mail: jaroslava.svobodova@ujep.cz, irena.lysonkova@ujep.cz \\ ${ }^{2}$ Faculty of Mechanical Engineering, University of West Bohemia. Univerzitní 2732/8, 30100 Plzeň. Czech Republic. E- \\ mail: mkrejci@kke.zcu.cz
}

In recent years, significant success has been achieved in surface treatment research, particularly in the field of physics, which deals with the surface properties of metals and their alloys, as well as new methods of coating preparation and thin films. These coatings and layers can modify material properties, i.e. increase oxidation and corrosion resistance, and improve frictional surface characteristics and other physical properties (e.g. electronics and optics). This article focuses on the mechanical properties of the coating, in particular on the hardness of composite PTFE coatings with WC micro and nano particles. In the experiment, samples of different concentrations of WC particles in the PTFE matrix were prepared, followed by a Vickers and Nanoindentation test. The difficulty in measuring the hardness of these layers is their small thickness. It is therefore difficult to measure the hardness by conventional methods, for example, Brinell or Vickers. The applicability of the individual methods (according to Vickers, nanoindentation test) we have experimentally verified and drawn the relevant conclusions and recommendations. Part of the contribution is also SEM documentation of created coatings. An important parameter is the coating technology itself when making these composite coatings. The technology can influence the distribution of particles in the matrix, which results in the homogeneity of the coating and the associated mechanical properties or tribological properties.

Keywords: Hardness, Nanoindentation Test, Composite Coatings, PTFE, WC Particles, Aluminium Substrate.

\section{Introduction}

For all alloys, the mechanical, physical, and chemical properties can be changed with precision chemical composition, technological parameters of forming, heat treatment, surface treatments, but also by creating coatings on the surface of the base material. [1]

Hardness is a very important property of any material that we need to know for the convenience of using individual materials for different purposes. We use various hardness tests to measure the hardness of materials. For aluminium and its alloys, it is often used the measurement of hardness by Brinell. Brinell hardness for Al materials ranges from $15 \mathrm{HBW}$ for pure aluminium to $140 \mathrm{HBW}$ for high strength hardenable alloys [2]. The purpose of most finishes and other related activities is to achieve a functional surface. At present, much greater requirements are put on all surfaces. However, the material is not able to meet this increased requirements, and therefore are applied the surfaces with conversion layers. Typically, the surface layer is a layer formed by modifying the surface of the base material, while the coating means another material applied to the surface of the base material (substrate). Surfaces specifically designed for aluminium surface treatment can be either chromating, chrome-free treatment or aluminium anodizing (anodic oxidation). These are known as a conversion coating. Each of these treatments has its advantages and disadvantages, and various technological applications and usage [3].

The surface layers or coatings are formed to improve the properties of the material surfaces. The latest coatings that we use to improve mechanical and tribological properties are for example PVD coatings, zirconium coatings created using sol-gel technology, as well as coatings based on amorphous carbon DLC or $\mathrm{TiO}_{2} / \mathrm{Al}_{2} \mathrm{O}_{3} / \mathrm{WC}$ and others based coatings. These are coatings with high hardness, corrosion resistance and very high resistance to adhesion of non-ferrous metals.

In this article, we deal with the composite coating which is composed of PTFE matrix and WC micro and nanoparticles. A composite coating is a material composed of at least two phases, separated from one to another by interface region. The major component is called matrix in which fillers are dispersed. The classification of composite coatings is based on various methods but the main is due to the type of micro or nanostructured fillers or the type of the matrix, where the fillers are dispersed. The properties of the final coatings depend on the type of the matrix and fillers. In fact, there are two types of the matrix which are organic and inorganic. Thus, there are four main groups of composite coatings and follows:

- Organic/inorganic composite coating (matrix/filler),

- Organic/organic composite coating,

- Inorganic/organic composite coating,

- Inorganic/inorganic composite coating [4].

The most used polymers for preparation of composite coatings can be listed for example: polyurethane, epoxy, polyethylene glycol (PEG, polyvinylidene fluoride (PVDF), polytetrafluoroethylene (PTFE), polystyrene, polyacrylate, polyester, polyamide and others. For inorganic matrix (metal or alloy matrix) are used methods including CVD - chemical vapour deposition, thermal plasma spray, powder metallurgy, PVD - physical vapour 
deposition. One of the method we use for preparation of the composite coating is sol-gel technology (Fig. 1). This method is suitable to obtain high quality films up to micron thickness and is a complementary of the physical deposition techniques [4 - 6].

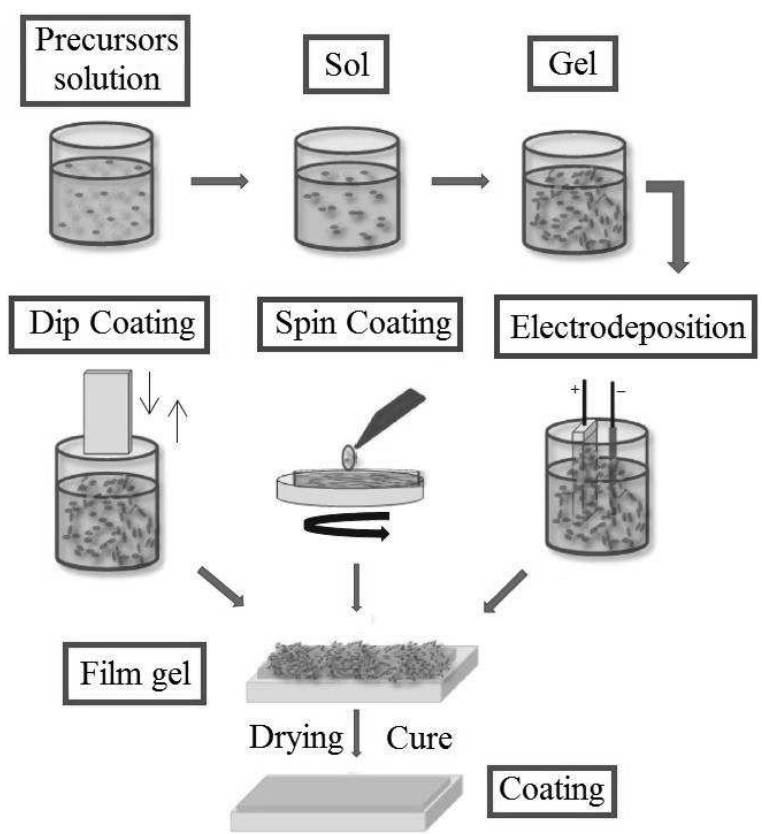

Fig. 1 Preparation of coatings by sol-gel method, spin coating method, electrodeposition [4]

For inorganic fillers, the types of micro and nanoparticles are for example carbides, nitrides, borides, oxides, metallic particles, nanodiamond. For organic micro and nanoparticles are the most used PTFE, PEO, PANi or nanocellulose and cellulose nanocrystal [4-6].

The Dip Coating method is used in the practical part of the article. This technique is widely used in the industry. The method is based on the soaking a substrate in a solution of composite and pulled up at a constant (controlled) speed. The substrate is covered with nanocomposite when it is removed from the solution. The amount of composite created on the substrate surface (in micro or nanoscale) depends on pulled up rate. These conditions can be controlled. There are two pulled out rates of the substrate: low pulled up rates and high pulled up rates. The low pulled up rates, there is the capillary regime where the rate of evaporation of the solvent is greater than that of the shrinkage of the plate. This means that the shorter the shrinking speed, the thicker the coating layer. The pulled up rates causes so-called drainage regime. That means the combination of the adhesion of the solution to the substrate and the gravity that forces the drainage of the solution. This causes thickening of the films as the shrinkage rate increases [4].

For evaluation of hardness, can be used the measurement of hardness or microhardness for traditional organic and inorganic coatings. However, for the composite and nanocomposite coatings, in order to study the effect of nanoparticles on the hardness of coatings. The addition of the solid particles to the polymer matrix to improve their mechanical and chemical properties is a very common method. These are generally particles such as $\mathrm{SiO}_{2}$, $\mathrm{Al}_{2} \mathrm{O}_{3}$, TiO2, WC, $\mathrm{ZnO}$ and $\mathrm{CaCO}_{3}$. There are many studies which are interested in the research in this field, as it is indicated in the references [4, $7-10]$.

\section{Materials and methods}

Within an experiment, the composite coatings were prepared on the surface of the Al-Si alloy substrate (AlSi10Mg). The composite coating is composed of polytetrafluoroethylene (PTFE) matrix with tungsten carbide (WC) particles (micro and nano scale mix). The coating was created using the Dip Coating method in laboratory conditions. Two types of experimental samples were prepared:

- Experimental samples - A - PTFE on the aluminium substrate

- Experimental samples - B - PTFE + WC particles with concentration $\mathbf{0 . 0 0 1 \%}$ WC per litre of the PTFE solution, $\mathbf{0 . 0 1 \%}$ WC per litre of the PTFE solution and $\mathbf{0 . 1 \%}$ WC per litre of the PTFE solution on the aluminium substrate.

The coating process is as follows: the first step of the coating technology is alkaline degreasing applied at an elevated temperature of $50-60^{\circ} \mathrm{C}$. After alkaline degreasing was used zirconium nano passivation and this type of pre-treatment works at room temperature. The thickness of this layer is around $30 \mathrm{~nm}$. The experimental samples were dried in the dryer with forced air circulation at $150^{\circ} \mathrm{C} 15$ minutes. After this operation, the composite coating was applied. This step contains the preparation of the liquid bath - PTFE + WC particles in the selected ratio. Thus prepared coating was dried in the dryer with forced air circulation at $100^{\circ} \mathrm{C} 30$ minutes. The coating baths were prepared with a defined amount of chemicals into the demineralized water. Time for each technology is different from 2 to 5 minutes for alkaline degreasing and zirconium nano passivation and 15 minutes for PTFE+WC.

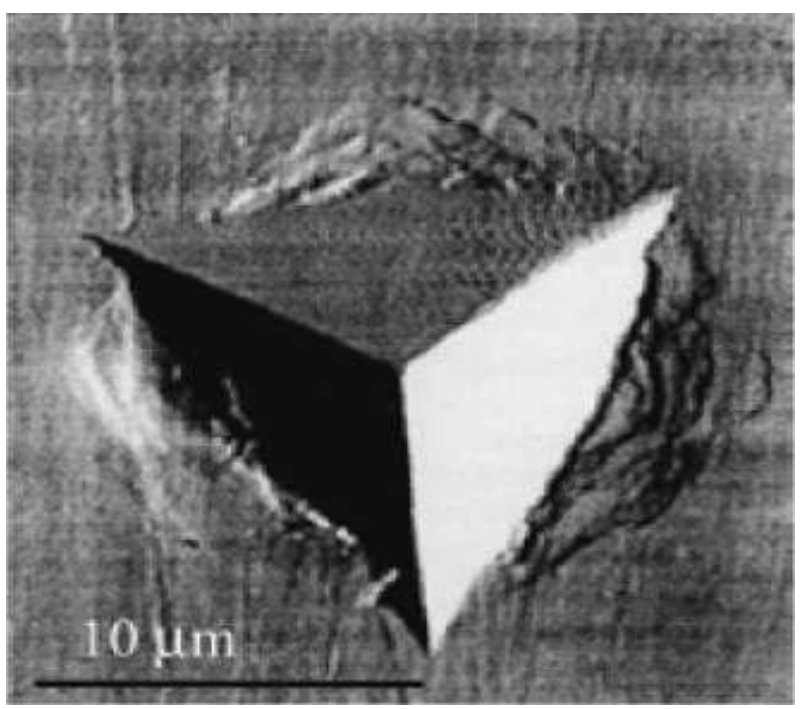

Fig. 2 Atomic force micrograph of a residual impression in steel made with a Berkovich's indenter [12] 
For evaluation of the micro and nanohardness were used the Vickers and Nanoindentation test.

In the measurement of nano-hardness, are used the same procedures as in the measurement of microhardness. However, to determine the mechanical properties of a film or coating from indentation experiments, the indentation depth must be at most a small fraction of the film or coating thickness. The load is even lower up to $1 \mathrm{nN}$. The impression depths can then get up to $0.1 \mathrm{~nm}$. The most commonly used nanoindenter is Berkovich's pyramid (Fig. 2). A nanoindentation test instrument provides experimental results in the form of a load-displacement curve for the loading and the unloading parts of the indentation process. As indicated in the reference [12], an analysis of the unloading data provides a value for the depth of contact at full load. The area of contact at full load is determined from the known angle or radius of the indenter. The hardness is found by dividing the load by the area of contact. The slope of the unloading curve provides a measure of elastic modulus [11-13].

\section{Results and discussion}

The first measurement we performed using the Brinell hardness test (ČSN EN ISO 6503-1). These methods of hardness measurement are not suitable for these types of coatings. The thickness is too low and the indenter measured the basic material, not the coating. This method does not provide relevant results.

The second method we used for hardness measurement of our samples was the Vickers hardness test (ČNN EN ISO 6507-1). The used load for this measurement has been set to HV10 - $10 \mathrm{kp}$ for $10 \mathrm{~s}$. The measured values for PTFE+WC, PTFE coatings, and basic material are shown in table 1 . The hardness values shown in table 1 are the average values from the measurement of the three samples from each group (1B, 2B, 3B, A, basic material) when each sample was measured fifteen times.

Tab. 1 Vickers hardness test average values

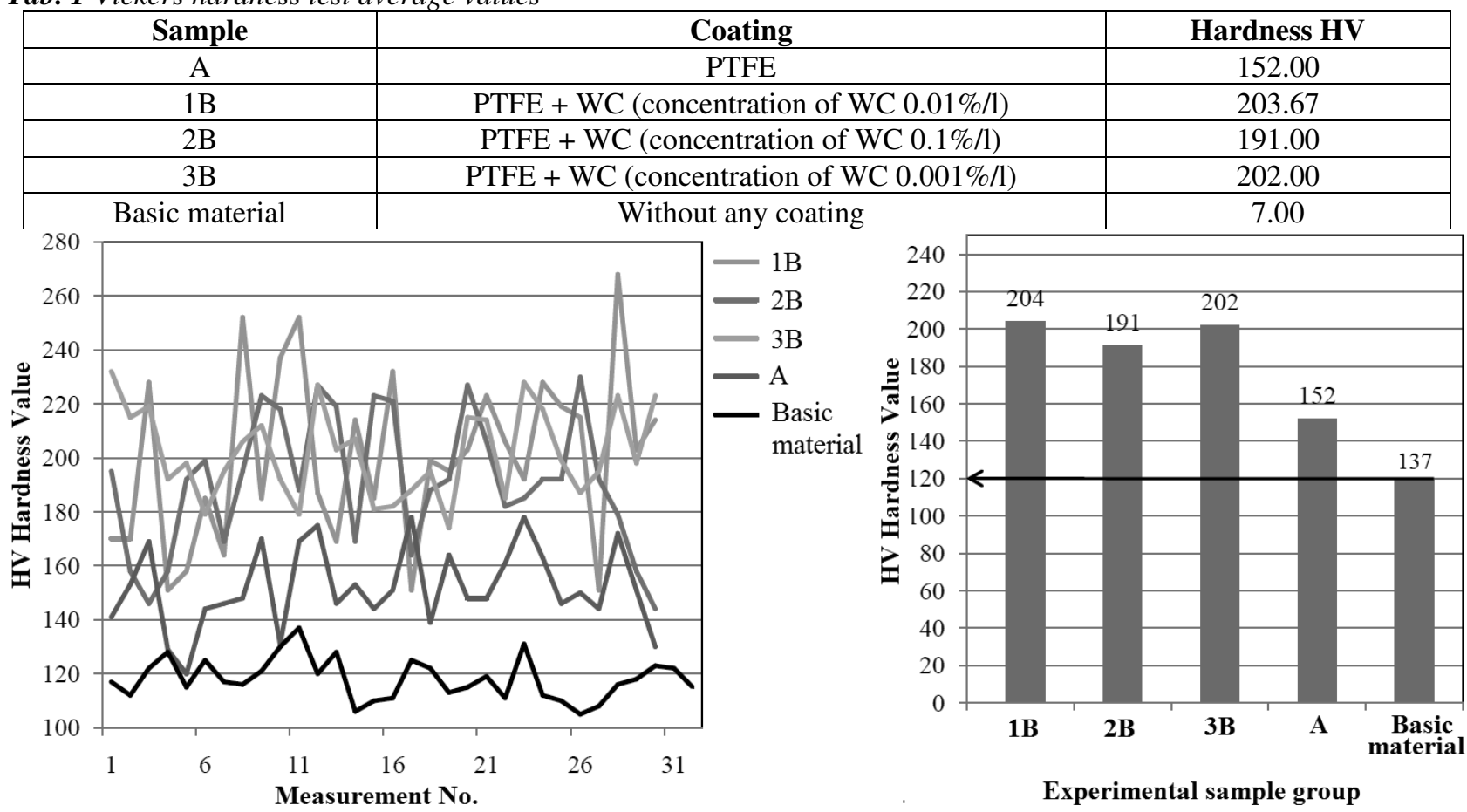

Fig. 3 Vickers hardness measurement - comparison of coatings

During the Vickers hardness measurement, it occurs to the big deviations between the measured values. The highest deviations were achieved on the sample of group 1B (with WC content $0.01 \%$, average standard deviation / s.d. / during the measurement around 31.99), lower in the sample group $2 \mathrm{~B}$ (WC $0.1 \%$, s.d. around 22.96) and lowest for sample group 3B (WC $0.001 \%$, s.d. around 16.30). For a PTFE coated sample without WC particles, the standard deviation was around 14.75 on average, which is similar to the sample with the lowest concentration of WC particles. For the base material, the standard deviation values of the measurement were the lowest, around 5.93. However, in this measurement, differences between individual sample groups were observed (Fig. 3). Coatings with the addition of nanoparticles WC had a higher hardness than the PTFE coating itself and the base material. The problem with Vickers hardness measurement is the distribution of particles on the surface of the experimental sample and the small coating thickness.

The third method we used for hardness measurement of our samples was the Nanoindentation hardness test. The values for the nanoindentation test were measured using an incisions matrix (Fig. 4-A), taking several incisions at once. It was measured under the following conditions:

- the incisions matrix was set to $10 \times 10$ incisions, the incisions gap was $35 \mu \mathrm{m}$,

- the maximum load was $5 \mathrm{mN}$ and the Berkovich type indenter was used (Fig. 4-B). 


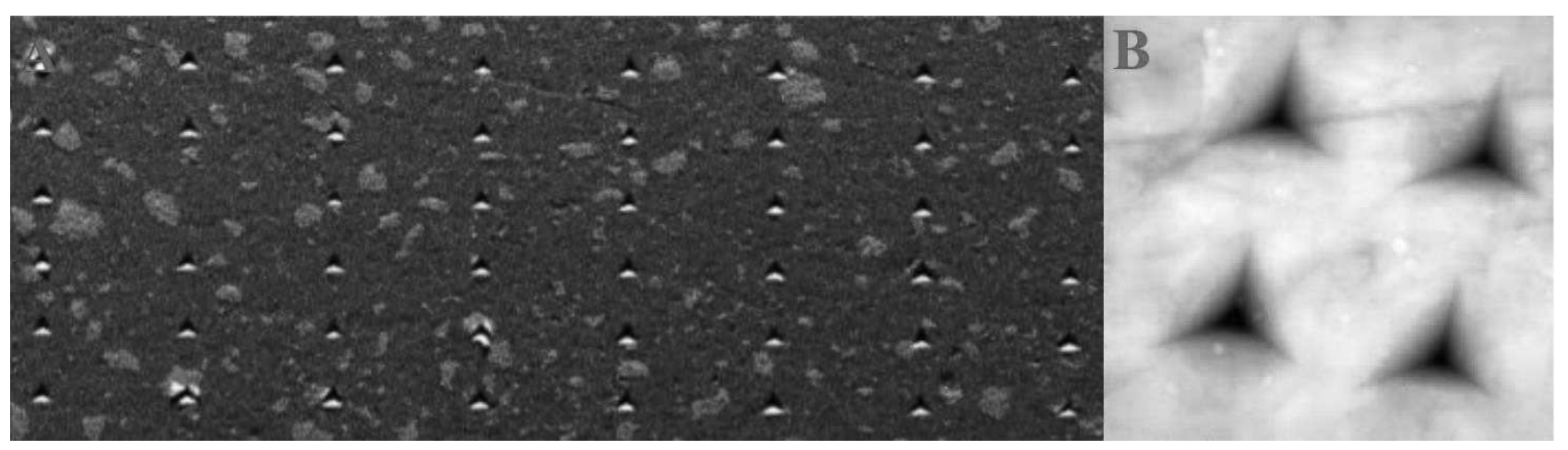

Fig. 4 Incisions matrix - A, Pyramidal indentation - Berkovich - B

In the experiment, the load of the indenter runs from zero to $5 \mathrm{mN}$, then followed a 4 -second delay at maximum load, the indenter is lightened (to 80\%) and it runs:

- Thermal Drift Correction;

- $\quad$ highlighting of the indenter;

- moving to the next incision place.

Then, further incisions can be performed in the same way and the experiment is terminated. End of the experiment must be confirmed and the specimen will move away from the indenter.

The first measurements were performed on a basic polished material (Al-Si alloy) and a basic material with
PTFE coating. With these experiments, the hardness values of the base material and PTFE were obtained. The data obtained serve to compare the hardness values on the other samples with the WC particles at different concentrations. In the Tab. 2, the average values are shown of the measured nanohardness and the standard deviation. Based on electron microscope documentation, the surface layer image (Fig. 5), the surface layer thickness was measured. The thickness is between 10 and $20 \mu \mathrm{m}$. From this thickness, we evaluated the maximum nanoindentation load of $5 \mathrm{mN}$ in order to make incisions only in the surface layer and not to break the layer.

Tab. 2 Average values of nanohardness and standard deviation of experimental samples

Tab. 2 Average values of nanohardness and standard deviation of experimental samples
\begin{tabular}{|c|c|c|c|c|}
\hline \multicolumn{5}{|c|}{ AVERAGE VALUE [GPa] } \\
\hline Basic material & A (PTFE) & 1B 0.01\% WC & 2B 0.1\% WC & 3B 0.001 \% WC \\
\hline 1.029856 & 1.516881 & 2.377672 & 1.810807 & 1.589744 \\
\hline \multicolumn{5}{|c|}{ STANDARD DEVIATION [GPa] } \\
\hline Basic material & A (PTFE) & 1B 0.01\% WC & 2B 0.1\% WC & 3B 0.001 \% WC \\
\hline 0.54956 & 1.198761 & 2.608725 & 2.378648 & 1.741689 \\
\hline
\end{tabular}

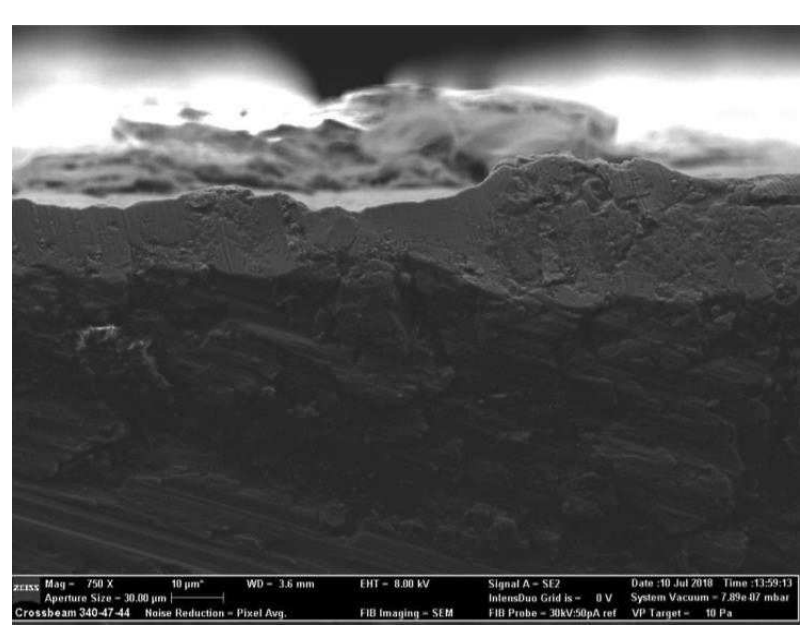

Fig. 5 Side view of experimental sample $2 B$ from electron microscope ZEISS

The measured hardness values are moving in a different range. This measurement also heavily depended on whether the incision was performed in a particle cluster or at a site with a lower particle concentration. In the case of nanometre measurements, the highest hardness value was measured for sample 1B - PTFE + WC $0.01 \%$. In the case of a sample with the lowest particle concentration, the hardness value is the lowest and is almost identical to the coating that contains no WC particles. The graphs of the nanoscale measurement for individual coatings are shown in Fig. 6.

For evaluation of homogeneity, coating morphology and distribution of particles on the surface of experimental samples we used the SEM analysis using the electron microscope TESCAN VEGA3. With SEM analysis we identified differently distributed particles on the surface of samples. Of course, their amount depended on the concentration in the PTFE matrix. However, the WC particles formed clumps and were not evenly distributed in the coating despite the fact that the bath was mixed during the coating technology. The coating thus became inhomogeneous in terms of particle distribution. The higher the concentration of particles, the larger the aggregates formed. Fig. 7 shows images of each experimental sample. 

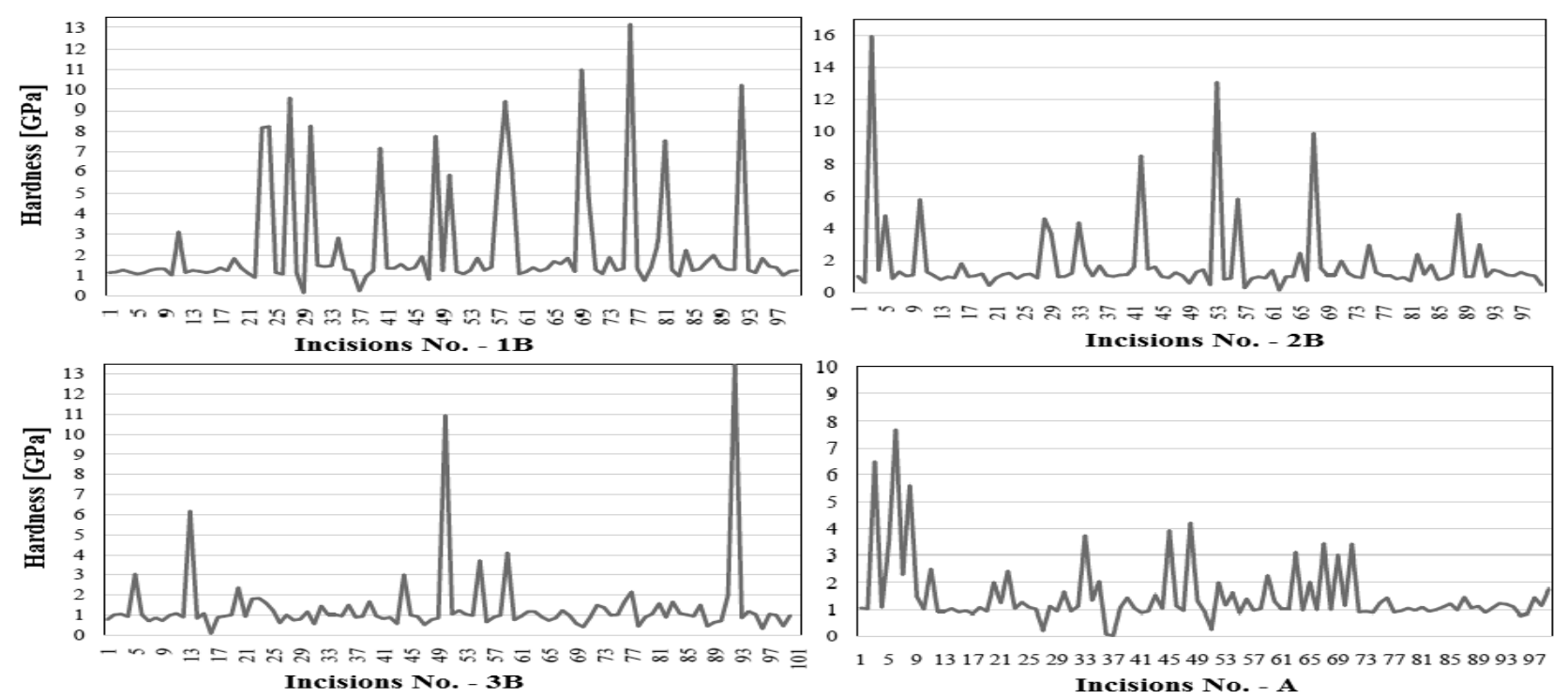

Incisions No. - $2 B$

Fig. 6 Nanohardness of the experimental samples - measurement graphs

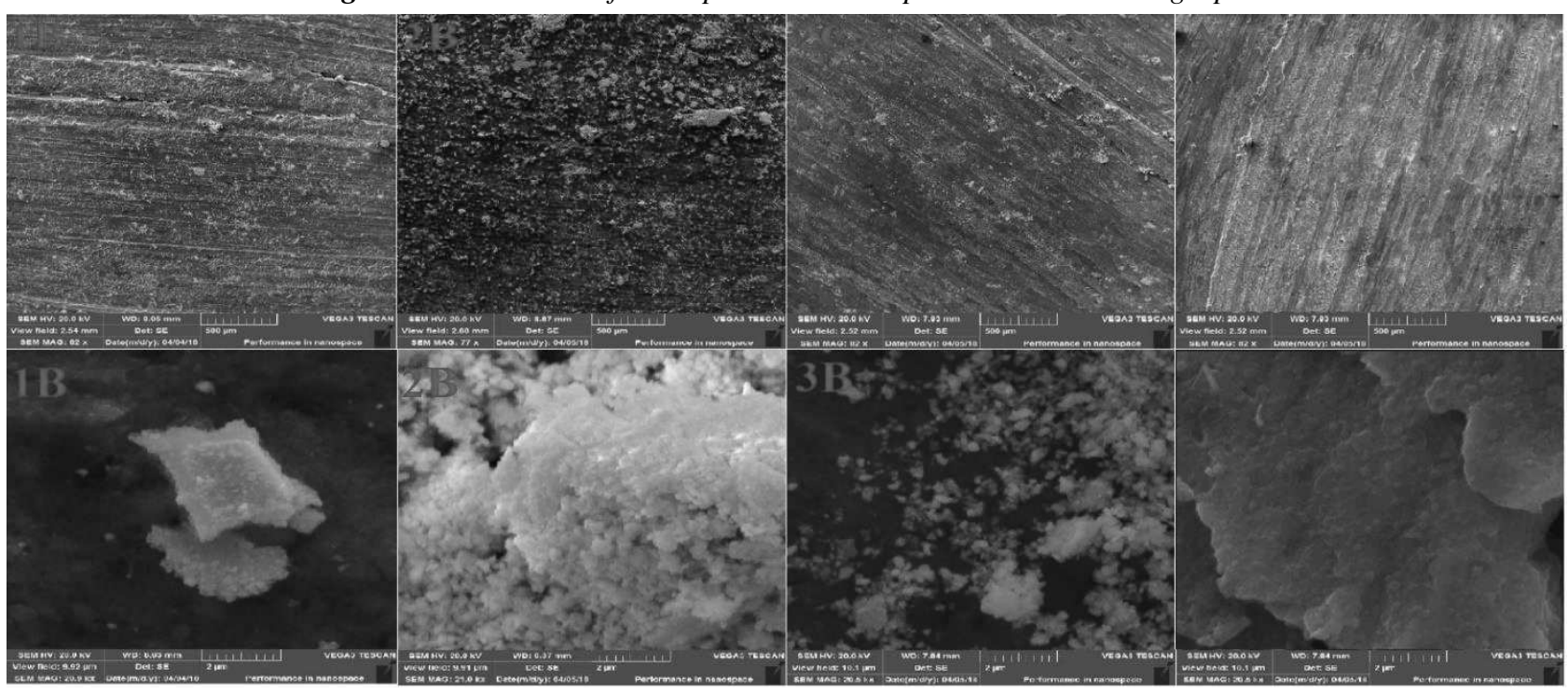

Fig. 7 SEM analysis of the experimental samples

\section{Conclusions}

- The Brinell hardness method is not suitable for this type of application - composite coatings up to $20 \mu \mathrm{m}$ thickness. During the measurement, the coating is damaged due to the high load force and the device detects only the hardness of the base material, regardless of the excluded coating.

- Vickers hardness measurement is more appropriate. This measurement method has already been able to determine differences between coatings. However, even this method is not the best. The measurements were accompanied by large differences in the measured values and the standard deviations of the measurements were relatively high.
- The most suitable method for measuring the hardness of nanocomposite coatings is the nanoindentation test. Due to the low load, it is possible to measure the actual hardness of the coating with the particles as the load is so small that the coating does not break.

- The hardness test is greatly influenced by the particle distribution in the PTFE matrix.

- The surface was documented by SEM analysis and it can be stated that the coating is not homogeneous. The particles are distributed unevenly in the PTFE matrix and form concentration-dependent clumps. The best particle size distribution was $0.1 \% \mathrm{WC}$ in the PTFE matrix. The recommendation is a change in coating technology, a better-mixed bath, sample placement, etc., which will be another research subject. 
- We consider this concentration $(0.1 \% \mathrm{WC}$ in PTFE matrix) to be the best considering the hardness, surface homogeneity and distribution of WC particles in the PTFE matrix.

\section{Acknowledgement}

Supported by the OP VVV Project Development of new nano and micro coatings on the surface of selected metallic materials - NANOTECH ITI II., Reg. No CZ.02.1.01/0.0/0.0/18_069/0010045.

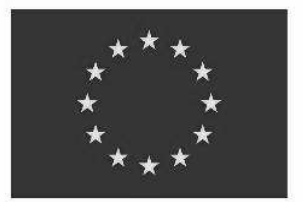

\section{EUROPEAN UNION}

European Structural and Investment Funds

Operational Programme Research,

Development and Education

\section{References}

[1] MICHNA, Š. et al. (2005). Encyklopedie hliníku, pp. 700. Adin, s. r. o., Prešov.

[2] DUŠEK, J. (2008). Tvrdost, mikrotvrdost, nanotvrdost - čisté kovy měřené metodou DSI. Ph.D. Thesis, Masarykova univerzita v Brně.

[3] WANG, Q. J., CHUNG, Y. (2013). Encyclopedia of Tribology, pp. 4139. Springer US.

[4] PHUONG, N., TUAN, A., PASCAL, C., CUONG, N. X. (2018). Properties, and Applications Nanocomposite Coatings: Preparation, Characterization. International Journal of Corrosion, pp. 19. Hindawi.

[5] ÇAĞATAY, D., AYSUN, A. (2018). The influence of Nano-TiO2 and Nano- $\mathrm{Al}_{2} \mathrm{O}_{3}$ Particles in Silicate Based Electrolytes on Microstructure and Mechanical Properties of Micro Arc Coated Ti6Al4V Alloy. Materials Research, Vol. 21, No. 5, pp. 613-616.

[6] GUILEMAN, J. M., DOSTA, S., NI,N J., MIGUEL, J. R. (2005). Study of the Properties of WC-Co Nanostructured Coatings Sprayed by High-Velocity Oxyfuel. JTTEE5, Vol. 14, No. 3, pp. 405-413.

[7] SUNG, L. P., COMER, J., FORSTER, A. M. et al. (2008). Scratch behaviour of nano-alumina/polyurethane coatings. Journal of Coatings Technology and Research (JCTR), Vol. 5, No. 4, pp. 419-430.

[8] SAJJADI, S. A., AVAZKONANDEHGHARAVOL, H., ZEBARJAD, S. M., MOHAMMADTAHERI, M., ABBASI, M., MOSSADDEGH, K. (2013). A comparative study on the effect of type of reinforcement on the scratch behavior of a polyacrylic-based nanocomposite coating. Journal of Coatings Technology and Research (JCTR), Vol. 10, No. 2, pp. 255261.

[9] BEHLER, K. D., STRAVATO, A., MOCHALIN, V., KORNEVA, G., YUSHIN, G., GOGOTSI, Y.
(2009). Nanodiamond-polymer composite fibres and coatings. ACS Nano, Vol. 3, No. 2, pp. 363369.

[10] BAKALOVÁ T., PETKOV, N., BAHCHEDZHIEV, H., KEJZLAR, P., LOUDA, P., ĎURÁK, M. (2017). Improving the Tribological and Mechanical Properties of an Aluminium Substrate by Deposition of TiCN Coatings. Manufacturing Technology, Vol. 17, No. 5, pp. 652-658.

[11] PANICH, N., WANGYAO, P. (2009). Nanoindentation for Accessing Nanomechanical Properties. Acta Metallurgica Slovaca, Vol. 15, No.1, pp. $55-62$.

[12] HAINSWORTH, S. V., CHANDER, H. W., PAGE, T. F. (1996). Analysis of nanoindentation loaddisplacement loading curves. J. Mater. Res., Vol. 11, pp. 1987- 1995.

[13] FISCHER-CRIPPS, A. C. (2011). Nanoindentation, Mechanical Engineering Series, pp. 282. Springer Science \& Business Media.

[14] BAKALOVÁ T., PETKOV, N., BAHCHEDZHIEV, H., KEJZLAR, P., LOUDA, P., ĎURÁK, M. (2017). Improving the Tribological and Mechanical Properties of an Aluminium Alloy by Deposition of AlSiN and AlCrSiN Coatings. Manufacturing Technology, Vol. 17, No. 6, pp. 824-830.

[15] BAKALOVÁ T., PETKOV, N., CHOLAKOVA, T., KAVÁN, F., BAHCHEDZHIEV, H. (2016). Mechanical Properties of Titanium-Aluminium Base Nanomultilayer Coatings. Manufacturing Technology, Vol. 16, No. 4, pp. 859-864.

[16] BAKALOVÁ T., PETKOV, N., BAHCHEDZHIEV, H., KEJZLAR, P., LOUDA, P., ĎURÁK, M. (2017). Comparison of Mechanical and Tribological Properties of TiCN and $\mathrm{CrCN}$ Coatings. Manufacturing Technology, Vol. 16, No. 5, pp. 854-858. 